\title{
Comparison of durability of treated wood using stake tests and survival analysis
}

\author{
Ikuo Momohara ${ }^{1 *}$ D, Haruko Sakai ${ }^{2}$ and Yuji Kubo ${ }^{3}$
}

\begin{abstract}
The stake test is widely used to evaluate the efficacy of wood preservatives. This test monitors the deterioration level observed in treated stakes partially inserted into the ground. The results are conventionally expressed as the relationship between deterioration levels and exposure periods. The preservative efficacy is compared among the stake groups treated with different retention levels based on the test results; however, there is no scientific basis for the comparison. We applied survival analysis to the conventional stake test to include a scientific basis to the test. Stakes impregnated with different types and retention levels of preservatives were subjected to deterioration at two test sites for approximately 30 years. The deterioration levels were monitored according to the conventional procedure and survival analysis was applied to the monitored data. Kaplan-Meier plots of the survival probabilities against the exposure periods indicated that there is a significant difference between the durability of the stakes treated with alkylammonium chloride (AAC-1) at K2 and K3 retention levels, whereas no significant difference was observed between those at K3 and K4 retention levels. Contrastingly, emulsified copper naphthenate (NCU-E) was found to be a reliable preservative, and the stakes impregnated with NCU-E showed a significant increase in durability in accordance with preservative retention. Alkaline copper quaternary (ACQ-1) also appeared to be a reliable preservative; however, the increase in stake durability after ACQ-1 treatment differed between the test sites. These results were verified using the modified Gehan-Breslow-Wilcoxon test with Holm's $p$ adjusting method.
\end{abstract}

Keywords: Stake test, Field test, Survival analysis, Wood preservative

\section{Introduction}

Wood is a material that mitigates climate change [1-3]; hence, many trials have been conducted to prolong its durability by increasing the service life of wooden materials. Although chemical or thermal modification processes have been recently adopted $[4,5]$, preservative impregnation by a vacuum-pressure process has been the most common method for increasing the durability of wooden materials [6-9].

Preservatives used for this process have been developed over several decades. For example, 30 years ago, chromated copper arsenate (CCA) was widely used for sill members in Japanese houses. However, 20 years

\footnotetext{
*Correspondence: momohara@ffpri.affrc.go.jp

${ }^{1}$ Kansai Research Center, Forestry and Forest Products Research Institute,

Fushimi, Kyoto 612-0855, Japan

Full list of author information is available at the end of the article
}

ago, CCA was completely replaced with safer preservatives, such as alkylammonium chloride (AAC-1), emulsified copper naphthenate (NCU-E), emulsified zinc naphthenate (NZN-E), and alkaline copper quaternary (ACQ-1) [10]. During the development of safe preservatives, the relationship between the durability of the treated wood and retention of impregnated preservatives was investigated. Our previous paper showed that the apparent mean service lives of the stakes impregnated with AAC-1 appeared to increase with increasing preservative retention at a low retention range, whereas they appeared saturated at a high retention range [11]. In contrast to this pattern, the stakes impregnated with ACQ-1 showed a trend that increased retention resulted in an increase in durability throughout the retention range [12]. These studies showed an association between durability and preservative retention;

\section{Springer Open}

C The Author(s) 2021. Open Access This article is licensed under a Creative Commons Attribution 4.0 International License, which permits use, sharing, adaptation, distribution and reproduction in any medium or format, as long as you give appropriate credit to the original author(s) and the source, provide a link to the Creative Commons licence, and indicate if changes were made. The images or other third party material in this article are included in the article's Creative Commons licence, unless indicated otherwise in a credit line to the material. If material is not included in the article's Creative Commons licence and your intended use is not permitted by statutory regulation or exceeds the permitted use, you will need to obtain permission directly from the copyright holder. To view a copy of this licence, visit http://creativecommons.org/licenses/by/4.0/. 
however, the difference in durability at different retention levels was not estimated effectively.

The reason for improper estimation was considered to be the lack of scientific rigor in the conventional stake test. Therefore, we improved the conventional stake test by including survival analysis and demonstrated that a combination of the conventional stake test and survival analysis could successfully determine the difference in durability of untreated wood with scientific rigor [13]. Here, we present the application of survival analysis to the stake test data and discuss the effect of preservative retention on the durability of treated stakes.

\section{Material and methods}

\section{Preparation of untreated stakes}

Stakes of Japanese cedar (Cryptomeria japonica) sapwood were prepared from green logs separately by the Nara Forest Research Center and Koshii Preserving. The dimensions of the stakes prepared by the Nara Center were $3 \times 3 \times 60 \mathrm{~cm}(\mathrm{~L})$, whereas those prepared by Koshii Preserving were $3 \times 3 \times 35 \mathrm{~cm}(\mathrm{~L})$. Western hemlock (Tsuga heterophylla) sapwood stakes were prepared by the Koshii Preserving, similar to the Koshii cedar stakes. The bottom end of the Koshii stakes was sharpened in the shape of a quadrangular pyramid, whereas no such processing was applied to the Nara stakes.

\section{Preparation of treated stakes}

The stakes were impregnated with wood preservatives that satisfied the quality specifications of JIS K1570:2013 [14]. The preservatives used were AAC-1, NCU-E, NZNE, ACQ-1, and emulsified zinc versaticate (VZN-E) (Table 1). The preservatives were impregnated according to the JIS A 9002:2012 process [15] at the Nara Forest Research Center or Koshii Preserving. The treated stakes were dried naturally under roofs until they were exposed to wood-attacking organisms at stake test sites. Estimated retention was calculated from the concentrations of preservatives in a working solution and amounts of the working solution impregnated into the stakes to determine the performance classification of the stakes according to the Japanese Agricultural Standards (JAS) for sawn lumber [16]. The stake conditions and test sites are listed in Table 1. As an exception, the stake groups indicated with two asterisks in Table 1 were ranked in a higher performance class because these stake groups were designed to estimate the minimal performance of treated stakes impregnated with the preservatives according to the JAS criteria for the sawn lumber. A part of the untreated stakes was kept without impregnation as the control.

\section{Exposure to wood-attacking organisms}

Stake tests were performed at the Nara or Ibaraki test sites (Table 2). The weather properties of the sites were similar, whereas the soil types of the sites were different, as mentioned in our previous paper [13]. The treated and untreated stakes were inserted into the ground at both test sites (Table 1). The insertion depth of all stakes was set to $30 \mathrm{~cm}$, even though the overall stake lengths were $60 \mathrm{~cm}$ (the Nara site) and $35 \mathrm{~cm}$ (the Ibaraki site). Stake deterioration levels were evaluated annually according to the JIS K 1571:2010 criteria at the ground level [17]. The data obtained from the exposure for one to three decades were used for further analyses.

\section{Data analysis by the conventional method}

Data analysis and service life determination were performed according to JIS K 1571:2010 [17]. When parts of the stakes were lost, the calculation was performed excluding the data of missing stakes.

\section{Data analysis according to survival analysis}

The service life of each stake was designated as the year when the deterioration level of the individual stake reached 2.5 [13], which was calculated according to Eq. (1):

$$
\mathrm{YSL}=Y 1+\frac{2.5-D L 1}{D L 2-D L 1},
$$

where YSL is the service life of a stake, $Y 1$ is the last year in which the deterioration level of the stake was below 2.5 , DL1 is the deterioration level of the stake observed at $Y 1$, and DL2 is the deterioration level of the stake observed one year after $Y 1$ [13].

Individual service life data were collected and used for survival analyses. Survival analysis was performed using R software (ver. 4.0.4) with the "survival" and "survminer" packages [18]. Significant differences were determined using the Peto \& Peto modification of the Gehan-Breslow-Wilcoxon test with Holm's $p$ adjustment method [19] $(p<0.05)$.

\section{Results and discussion}

\section{Results of conventional stake tests}

The characteristics of the stake groups and service lives of the stakes are listed in Table 1. The results of the field test for most of the stake groups have been reported in our previous papers [11, 12, 20, 21].

Before discussing the results of the stake test, it is necessary to highlight the following two points. First, this study included preliminary data, and the estimated retention of some stake groups, such as AAC-1, whose estimated retention was $4.3 \mathrm{~kg} / \mathrm{m}^{3}$, was set just below the JAS requirement. In this study, the performance 
Table 1 Characteristics of stake group and their apparent service lives

\begin{tabular}{|c|c|c|c|c|c|c|}
\hline Preservative & $\begin{array}{l}\text { Estimated retention } \\
\left(\mathrm{kg} / \mathrm{m}^{3}\right)\end{array}$ & $\begin{array}{l}\text { Performance } \\
\text { classification }\end{array}$ & $\begin{array}{l}\text { Abbreviation of } \\
\text { stakes }\end{array}$ & Site name & Wood species & Service life \\
\hline \multirow[t]{4}{*}{ AAC-1 } & 4.0 & K2 & AAC-K2 & Nara & Japanese cedar & 8.5 \\
\hline & 6.1 & K3 & AAC-K3 & & & 8.5 \\
\hline & 3.4 & K2 & AAC-K2 & & & 4.5 \\
\hline & 5.8 & K3 & AAC-K3 & & & 6 \\
\hline \multirow[t]{6}{*}{$A A C-1^{a}$} & 4.3 & $K 3^{b}$ & AAC-K3 & & & 7 \\
\hline & 8.8 & $K 4^{b}$ & AAC-K4 & & & 9 \\
\hline & 13.2 & K4 & AAC-K4 & & & 10 \\
\hline & 15.9 & K4 & AAC-K4 & & & 9 \\
\hline & 25.2 & K4 & AAC-K4 & & & 9 \\
\hline & 27.2 & K4 & AAC-K4 & & & 9 \\
\hline$A A C-1$ & 5.4 & K3 & AAC-K3 & & & 12 \\
\hline \multirow[t]{3}{*}{ NCU-E } & 0.5 & K2 & NCU-K2 & & & 12 \\
\hline & 1.0 & K3 & NCU-K3 & & & 17 \\
\hline & 1.5 & K4 & NCU-K4 & & & 20 \\
\hline \multirow[t]{2}{*}{ NZN-E } & 1.0 & $\mathrm{~K} 2$ & NZN-K2 & & & 6 \\
\hline & 1.5 & K2 & NZN-K2 & & & 7.5 \\
\hline \multirow[t]{3}{*}{ VZN-E } & 1.2 & $\mathrm{~K} 2^{\mathrm{b}}$ & VZN-K2 & & & 7 \\
\hline & 2.5 & K3 & VZN-K3 & & & 9 \\
\hline & 3.4 & K3 & VZN-K3 & & & 9 \\
\hline \multirow[t]{13}{*}{ ACQ-1 } & 2.8 & K3 & ACQ-2.8 & & & 15 \\
\hline & 3.8 & K3 & ACQ-3.8 & & & 19 \\
\hline & 4.5 & K3 & ACQ-4.5 & & & 22 \\
\hline & 1.28 & $\mathrm{~K} 2^{\mathrm{b}}$ & ACQ-CK2 & Ibaraki & & 14 \\
\hline & 1.92 & K2 & ACQ-cK2 & & & 20 \\
\hline & 2.57 & $K 3^{b}$ & ACQ-cK3 & & & $>29$ \\
\hline & 3.85 & K3 & ACQ-cK3 & & & $>29$ \\
\hline & 5.13 & $\mathrm{~K} 4^{\mathrm{b}}$ & ACQ-cK4 & & & $>29$ \\
\hline & 1.28 & $\mathrm{~K} 2^{\mathrm{b}}$ & ACQ-hK2 & & Western hemlock & 15.5 \\
\hline & 1.92 & $\mathrm{~K} 2$ & ACQ-hK2 & & & 16.5 \\
\hline & 2.57 & $\mathrm{~K} 3^{\mathrm{b}}$ & ACQ-hK3 & & & 26.5 \\
\hline & 3.85 & K3 & ACQ-hK3 & & & $>29$ \\
\hline & 5.13 & $\mathrm{~K} 4^{\mathrm{b}}$ & ACQ-hK4 & & & $>29$ \\
\hline
\end{tabular}

a Preservative contained termiticides

${ }^{b}$ Preservative retention of stakes was just below the value required by the JAS 1083 [16]

Table 2 Characteristics of the two test sites

\begin{tabular}{llll}
\hline Name of test site & \multicolumn{2}{l}{ Location } & Soil type \\
\cline { 2 - 3 } & Latitude & Longitude & \\
\hline Ibaraki & $36^{\circ} 2^{\prime} 08.2^{\prime \prime}$ & $140^{\circ} 6^{\prime} 01.0^{\prime \prime}$ & Andosol \\
Nara & $34^{\circ} 28^{\prime} 29.8^{\prime \prime}$ & $135^{\circ} 48^{\prime} 54.2^{\prime \prime}$ & Gleysol \\
\hline
\end{tabular}

classification of these stake groups was ranked in the next higher class because these stake groups were prepared to estimate the minimal performance of treated wood for each JAS criterion. The stakes with two asterisks in Table 1 are the stakes that were ranked in a higher class of the JAS criterion. Second, AAC-1 stakes with a single asterisk (Table 1) were impregnated with AAC-1 containing $1 \%$ phoxim or $1 \%$ chlorpyrifos in their working solution. However, service lives appeared similar to those of the other AAC-1. As we concluded that termiticide did not influence the service lives of the stakes, further analysis was performed assuming that all stake groups impregnated with AAC- 1 were of the same quality despite the contamination of phoxim or chlorpyrifos.

As shown in Table 1, the results of the conventional test indicate that the service lives of the stakes impregnated with AAC-1 varied from 4.5 to 12 years. The relationship between the estimated retention and service life is 
unclear. NZN-E and VZN-E also showed a similar tendency, with no clear relationship between the estimated retention and service life. Contrary to these preservatives, the stakes impregnated with ACQ-1 or NCU-E appeared to be affected by the estimated retention level. The estimated ACQ-1 retention increased from 2.8 to $4.5 \mathrm{~kg} / \mathrm{m}^{3}$ at the Nara site; the service life increased from 15 to 22 years. The same effect was observed in the stakes impregnated with NCU-E. Regarding the influence of wood species, the Japanese cedar stakes appeared to perform better than the western hemlock stakes when treated with ACQ-1 at a level higher than the $\mathrm{K} 3$ criteria of JAS.

\section{Results of survival analysis}

As discussed in our previous paper [13], the service life determined by the conventional method is simple and useful; however, mathematical ambiguity remains in the calculation process. Because there is a misuse of the ordinal scale as a proportional scale, it is mathematically inaccurate to calculate the mean of the deterioration levels collected by annual observation using the ordinal scale. Therefore, it is also incorrect to discuss the differences in durability from the apparent mean values calculated by the conventional procedure. To overcome this inaccuracy, we developed a conventional stake test method with the addition of survival analysis and demonstrated that the novel method is useful for comparing durability among groups of untreated stakes [13]. Survival analysis has another advantage in that it can handle missing data. Some stakes were accidently lost during the long exposure period. In other cases, some stakes were collected, for example, to check for retention midway through the test. In such cases, survival analysis can treat the lost data as censored data and draw a survival curve with mathematical robustness [22].

Here, we apply a novel method to the conventional stake test data of the stakes treated with different preservative retention levels and discuss the significant differences among durability of the stakes treated with different preservatives and retention levels.

The Kaplan-Meier method was applied to compare the durability of stakes treated with wood preservatives, for which the selection of the event was important. The event was defined as the time at which the stake deterioration level was 2.5 [13].

\section{Comparison of AAC-1 stakes of different performance classification}

The Kaplan-Meier curves for the stakes impregnated with AAC-1 are shown in Fig. 1. The Y-axis indicates the survival probability, which is the ratio of stakes that did not reach the deterioration level of 2.5. The difference

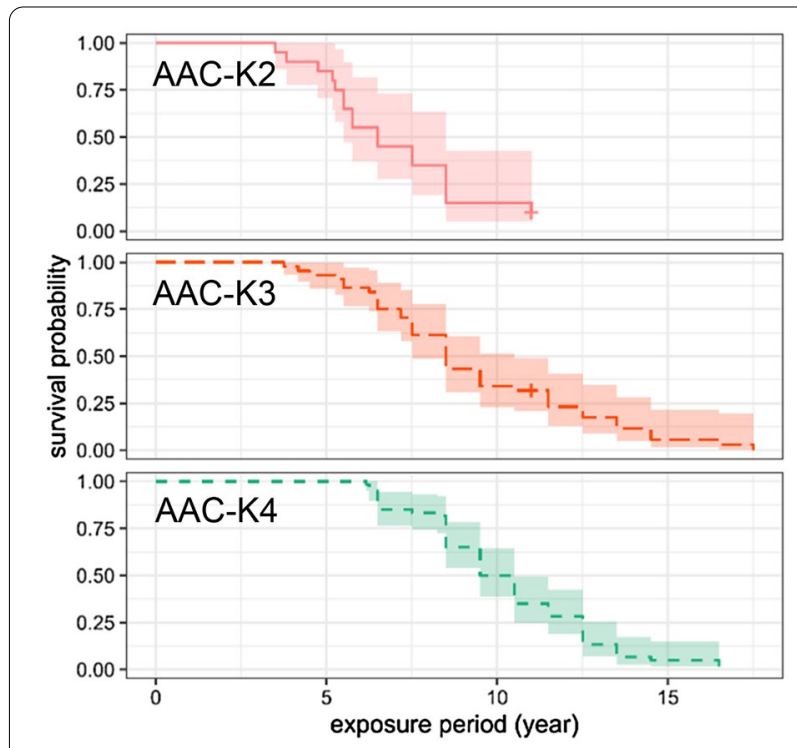

Fig. 1 Kaplan-Meier curves for stakes impregnated with AAC-1 at different performance classifications. Information on the stakes is shown in Table 1. AAC-1 alkylammonium chloride

Table 3 Adjusted $p$ value between each stake group treated with AAC-1

\begin{tabular}{lll}
\hline Abbreviation & AAC-K2 & AAC-K3 \\
\hline AAC-K3 & 0.015 & - \\
AAC-K4 & 0.000 & 0.072 \\
\hline
\end{tabular}

in the lines indicates the difference in the performance classification shown in Table 1. Among stakes impregnated with AAC-K2, a deterioration level of 2.5 was first reached after a 3.5-year exposure, and half of the stakes reached a deterioration level of 2.5 in 7 years. In the case of AAC-K3 and AAC-K4, deterioration of the first stake appeared after 3.5 and 6.3 years of exposure, respectively, and it took 8.5 and 10 years, respectively, for half of the stakes to reach the deterioration level of 2.5. Tick marks on the $\mathrm{K} 2$ and $\mathrm{K} 3$ data after the 11-year exposure indicate that some stakes were lost or removed before they reached the deterioration level of 2.5 .

Multiple comparisons revealed a significant difference between the durability of AAC-K2 and AAC-K3 and that between AAC-K2 and AAC-K4 (Table 3). Contrastingly, no significant differences were observed between AAC$\mathrm{K} 3$ and AAC-K4. The fact that some AAC-K4 contained high retention values, suggests that no significant difference can be observed between commercial AAC-K3 and $\mathrm{AAC}-\mathrm{K} 4$ lumbers because lumber manufacturers impregnate wood preservatives at retention levels just above the minimum value required for each performance 


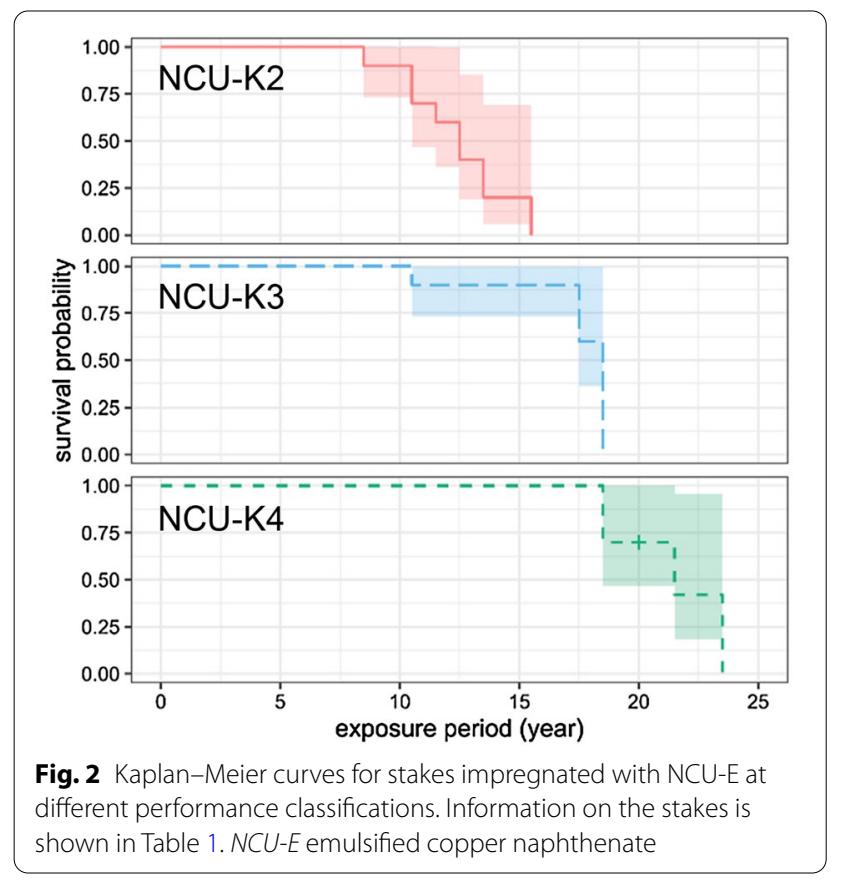

Table 4 Adjusted $p$ value between each stake group treated with NCU-E

\begin{tabular}{lll}
\hline Abbreviation & NCU-K2 & NCU-K3 \\
\hline NCU-K3 & 0.001 & - \\
NCU-K4 & 0.000 & 0.001 \\
\hline
\end{tabular}

class. The AAC-K4 lumber appears unsuitable for use in severe ground contact conditions.

\section{Comparison of emulsified preservatives}

NCU-E, NZN-E, and VZN-E consist of oil-soluble preservatives, surfactants, and water. To investigate performance of NCU-E at different retention levels, the Kaplan-Meier curves for the stakes containing NCU-E at K2-K4 performance classes were plotted (Fig. 2). The graph indicates that the increase in retention increased the service lives because the first stake that reached the deterioration level of 2.5 appeared in ascending order of the performance classification. Additionally, the exposure year when half the stakes reached the deterioration level of 2.5 increased with the increase in performance classifications. Multiple comparisons performed to confirm these observations revealed that there is a significant difference among the service lives of the stakes treated with NCU-E at different performance classifications (Table 4). The survival probability of NCU-E stakes, especially that of the K3 and K4 performance classes, decreased drastically in the late stages of the Kaplan-Meier curves. The downward trend observed in NCU-K3 and NCU-K4 was not similar to that observed in the stakes treated with AAC-1 (Fig. 1).

Figure 3 shows the effects of copper and zinc on the service life of the stake. The survival probability of NCU$\mathrm{K} 3$ is displayed by a higher line than that of VZN-K3 after 5 years of exposure, which indicates that NCU-K3 is more durable than VZN-K3, although both stakes were considered as having the same performance classification. Additionally, NCU-K2 was more durable than VZN-K2 or NZN-K2. The difference in durability between NCU-E
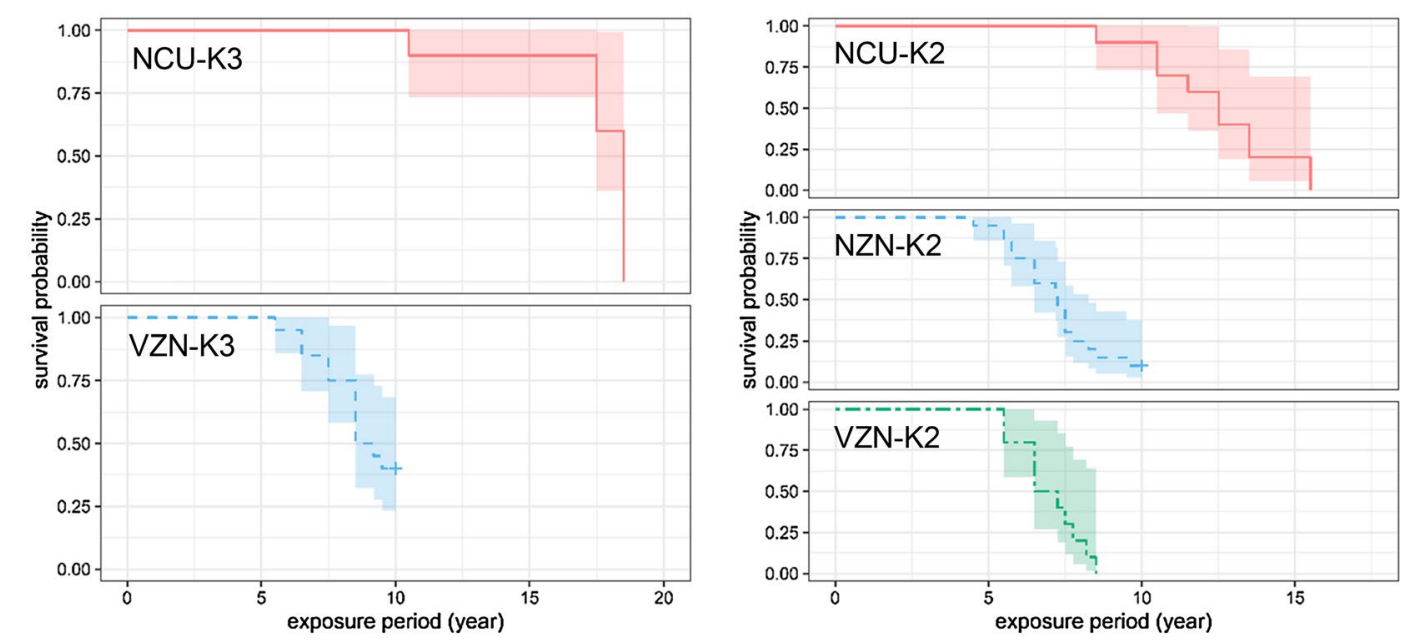

Fig. 3 Kaplan-Meier curves for stakes impregnated with emulsified preservative. Left: stakes impregnated with preservatives at K3 performance classification. Right: stakes impregnated with preservatives at K2 performance classification. Information on the stakes in each performance classification is shown in Table 1 
Table 5 Adjusted $p$ value between each stake group treated with emulsified preservatives

\begin{tabular}{llll}
\hline Abbreviation & NCU-K3 & NCU-K2 & NZN-K2 \\
\hline VZN-K3 & 0.004 & - & - \\
NZN-K2 & - & 0.000 & - \\
VZN-K2 & - & 0.000 & 0.724 \\
\hline
\end{tabular}

and the other emulsified preservatives was shown by multiple comparisons (Table 5). These results reveal that NCU-E is the most reliable preservative among the three emulsified formulations used for ground contact conditions which is in good agreement with those reported by Woodward et al. [23] who found that copper naphthenate provided greater protection than zinc naphthenate with similar retention levels in a stake test in Mississippi.

\section{Comparison of ACQ-1-impregnated stakes at different retention levels}

The effect of ACQ-1 retention on stake durability is shown in Fig. 4. The test was performed at the Nara site and the performance classification of all stakes was set to $\mathrm{K} 3$ and the retention levels of these stakes varied from 2.8 to $4.5 \mathrm{~kg} / \mathrm{m}^{3}$. As shown in the figure, an increase in ACQ-1 retention appeared to increase stake durability, which was confirmed by multiple comparison analysis (Table 6). Contrary to AAC-1-impregnated stakes (Fig. 1; Table 3), stakes impregnated with ACQ-1 showed

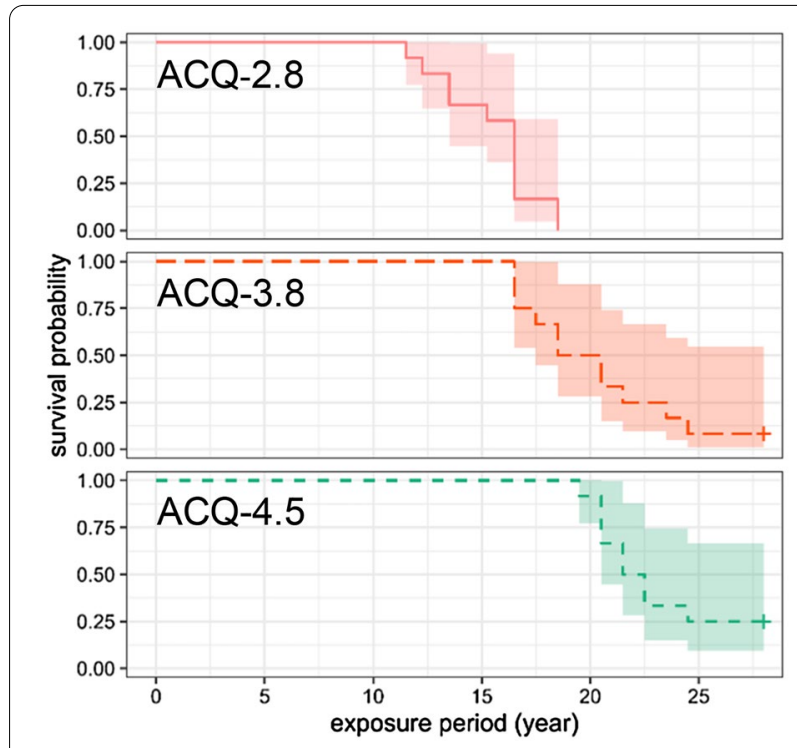

Fig. 4 Kaplan-Meier curves for stakes impregnated with ACQ-1 at different retention at the Nara site. Information on the stakes in each performance classification is shown in Table 1. ACQ-1 alkaline copper quaternary
Table 6 Adjusted $p$ value between each stake group treated with ACQ-1

\begin{tabular}{lll}
\hline Abbreviation & ACQ-2.8 & ACQ-3.8 \\
\hline ACQ-3.8 & 0.002 & - \\
ACQ-4.5 & 0.000 & 0.038 \\
\hline
\end{tabular}

a significant increase in durability with an increase in ACQ-1 retention.

\section{Comparison of ACQ-1-impregnated stakes of different species with different retention levels}

To check whether ACQ-1 retention level correlates with the durability of the stakes impregnated with ACQ-1, a similar test was performed at the Ibaraki site. Figure 5 shows the survival probabilities of Japanese cedar and Western hemlock stakes impregnated with ACQ1. It is worth mentioning that the length of stakes used at this site was different from that of the stakes used at the Nara site. The stakes at the Ibaraki site were $35 \mathrm{~cm}$ long, whereas those at the Nara site were $60 \mathrm{~cm}$ long. As a result, the retention at the ground level must have been higher at the Ibaraki site than at the Nara site. The soil at the Nara site was damp compared to that of the Ibaraki site because the soil types at the Nara and Ibaraki sites are Gleysol and Andosol, respectively. These factors probably affected the difference in the deterioration rates at the two test sites $[13,24]$.

As shown in the figure, the results obtained from the Ibaraki site are unclear because the exposure period is too short to estimate stake durability, especially at the high ACQ-1 retention level. The test for significance also suggests that no significant differences were observed for stake durability at high ACQ-1 retention (Table 7). A further exposure period is necessary for the precise estimation of the durability of stakes treated with ACQ-1 of performance classes K3 and K4. Contrastingly, the stakes of performance class $\mathrm{K} 2$ showed significantly lower durability than stakes in the K3 and K4 performance classes.

The efficacy of ACQ-1 impregnation for different species was also comparable (Fig. 5). The Kaplan-Meier plots of the Japanese cedar stakes and the Western hemlock stakes impregnated with ACQ-1 at three retention levels showed similar curves. The $p$ values of the Peto \& Peto modification of the Gehan-Breslow-Wilcoxon test for $\mathrm{K} 2$, K3, and $\mathrm{K} 4$ stakes were $0.69,0.89$, and 0.26 , respectively, which suggests that there is no significant difference between the durability of the two species impregnated with ACQ-1. In other words, ACQ-1 adds similar durability to both the Japanese cedar and the Western hemlock stakes. 

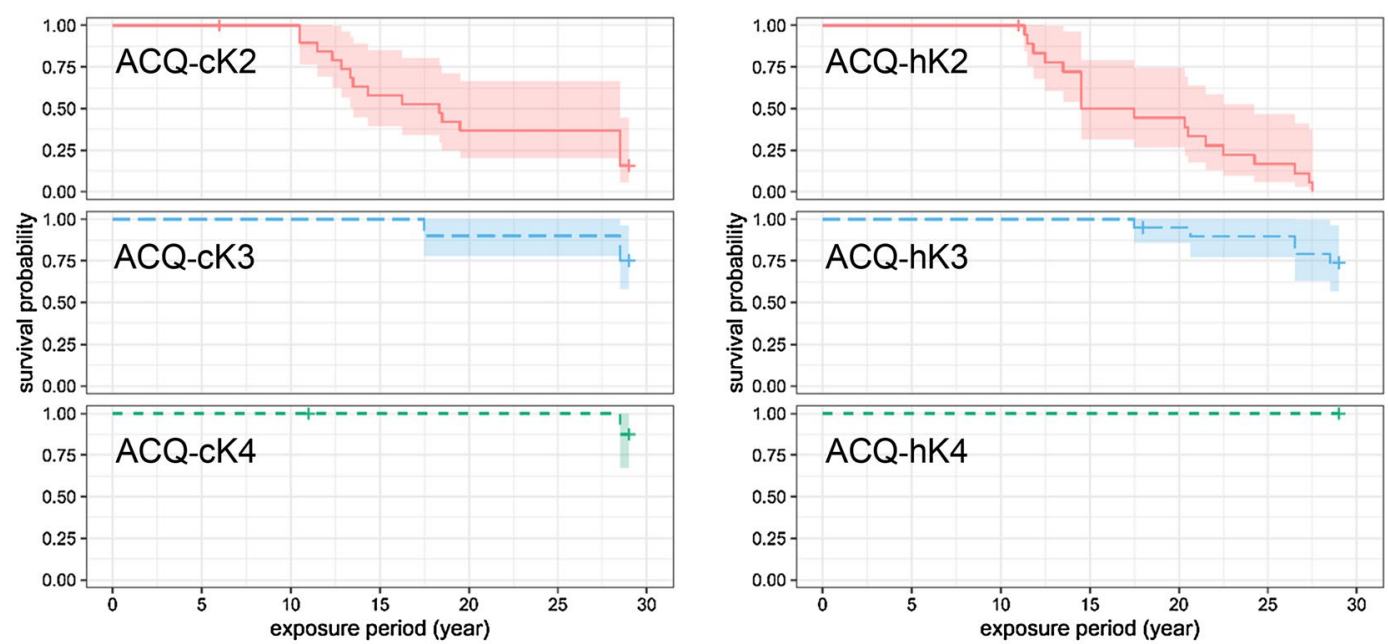

Fig. 5 Kaplan-Meier curves for stakes impregnated with ACQ-1 at the Ibaraki site. Left: Japanese cedar stakes. Right: western hemlock stakes. Information on the stakes in each performance classification is shown in Table 1. ACQ-1 alkaline copper quaternary

Table 7 Adjusted $p$ value between stakes treated with ACQ-1 in different performance classifications

\begin{tabular}{llllll}
\hline Abbreviation & ACQ-cK2 & ACQ-cK3 & Abbreviation & ACQ-hK2 & ACQ-hk3 \\
\hline ACQ-cK3 & 0.000 & - & ACQ-hK3 & 0.000 & - \\
ACQ-cK4 & 0.003 & 0.441 & ACQ-hK4 & 0.000 & 0.087 \\
\hline
\end{tabular}

sary to compare the durability of the stakes impregnated with ACQ-1 at the K3 and K4 classes at the Ibaraki site.

- Our present data suggest that ACQ-1 has similar efficacies in both Japanese cedar and Western hemlock.

\section{Conclusion}

1) We applied a survival analysis to the conventional stake test to compare the efficacy of preservatives.

2) The Kaplan-Meier curve was useful to estimate the efficacy of the preservative at different retention levels.

3) The durability of treated stakes at different retentions could be compared using the modified Gehan-Breslow-Wilcoxon test with Holm's $p$ adjusting method with scientific robustness.

4) The test for significance revealed that:

- The durability of stakes impregnated with AAC-1 increased with the increase in AAC-1 retention from $\mathrm{K} 2$ to $\mathrm{K} 3$; however, the difference was not significant from $\mathrm{K} 3$ to $\mathrm{K} 4$.

- NCU-E was a more reliable preservative than the other emulsified preservatives containing zinc. The durability of stakes impregnated with NCU-E increased in accordance with the increase in NCU-E retention.

- ACQ-1 retention level significantly affected the durability of the ACQ-1-impregnated stakes at the Nara test site. This correlation was partly observed at the Ibaraki site. A further exposure period is neces-

\section{Abbreviations}

CCA: Chromated copper arsenate; AAC-1: Alkylammonium chloride; NCU-E: Emulsified copper naphthenate; NZN-E: Emulsified zinc naphthenate; VZN-E: Emulsified zinc versaticate; ACQ-1: Alkaline copper quaternary; JIS: Japanese Industry Standards; JAS: Japanese Agricultural Standards.

\section{Acknowledgements}

We are grateful to the staff of the Forestry and Forest Products Research Institute (Ibaraki site) and Nara Forest Research Institute (Nara site) for their help in managing the test sites.

\section{Authors' contributions}

All three authors contributed equally to this manuscript. HS was responsible for the stake test at the Nara test site. YK was responsible for the stake test of the ACQ-impregnated stakes at the Ibaraki test site. IM contributed to the survival analysis of the data from HS and YK. IM mainly wrote the manuscript and the other authors revised the manuscript. All authors read and approved the final manuscript.

\section{Funding}

None.

\section{Availability of data and materials}

The data sets analyzed during the current study are available from the corresponding author upon reasonable request.

\section{Declarations}

\section{Competing interests}

The authors declare that they have no competing interests. 


\section{Author details}

${ }^{1}$ Kansai Research Center, Forestry and Forest Products Research Institute, Fushimi, Kyoto 612-0855, Japan. ${ }^{2}$ Nara Forest Research Institute, Takatori, Takaichi-gun, Nara 635-0133, Japan. ${ }^{3}$ Koshii Preserving Co., Ltd., Suminoeku, Osaka 559-0026, Japan.

Received: 5 September 2021 Accepted: 28 October 2021

Published online: 06 November 2021

\section{References}

1. Tsunetsugu Y, Tonosaki M (2010) Quantitative estimation of carbon removal effects due to wood utilization up to 2050 in Japan: effects from carbon storage and substitution of fossil fuels by harvested wood products. J Wood Sci 56:339-344

2. Soimakallio S, Saikku L, Valsta L, Pingoud K (2016) Climate change mitigation challenge for wood utilization the case of Finland. Environ Sci Technol 50(10):5127-5134

3. Leskinen P, Cardellini G, González-García S, Hurmekoski E, Sathre R, Seppälä J, Smyth C, Stern T, Verkerk PJ (2018) Substitution effects of woodbased products in climate change mitigation. From Science to Policy 7. Eur Forest Inst. https://doi.org/10.36333/fs07

4. Rowell RM (2014) Acetylation of wood - a review. Int J Lignocellulosic Prod 1:1-27

5. Esteves BM, Pereira HM (2009) Wood modification by heat treatment: a review. BioResources 4:370-404

6. Preston AF (2000) Wood preservation: trends of today that will influence the industry tomorrow. Forest Prod J 50(9):12-19

7. Richardson BA (2002) Wood preservation. E\& FN Spon, London

8. Lebow ST (2010) Wood preservation. In: Forest Products Laboratory (ed) Wood handbook (Centennial Edition), 15th edn. Madison, Department of Agriculture Forest Service

9. Salminen E, Valo R, Korhonen M, Jernlås R (2014) Wood preservation with chemicals: best available techniques (BAT). https://www.ippc.int/static/ media/files/publications/en/2014/09/04/17_ewgwoodhandicrafts_ 2014_sep.pdf. Accessed 1 Apr 2021.

10. Momohara I (2018) Diversification of wood preservatives and their treatment process - present and future. Wood Prot 44:176-179

11. Sakai H, Iwamoto Y, Nakamura Y (2008) Progress on damage and service life of wood stakes impregnated with IPBC or DDAC. Wood Preserv $34: 112-118$
12. Sakai H, Yasugi R, Iwamoto Y, Masuda K (2019) Progress on damage of wood stakes impregnated with ACQ revealed by observation for 25 years. Bull Nara Forest Res Inst 48:43-48

13. Momohara I, Sakai H, Kurisaki H, Ohmura W, Kakutani T, Sekizawa T, Imamura Y (2021) Comparison of natural durability of wood by stake tests followed by survival analysis. J Wood Sci 67:44

14. JIS K 1570 (2010) Wood preservatives. Japanese Industry Standards Committee, Japan

15. JIS A 9002 (2012) Preservative treatments of wood products by pressure processes. Japanese Industry Standards Committee, Japan

16. JAS 1083 (2019) Sawn lumber. Ministry of Agriculture, Forestry and Fisheries, Japan

17. JIS K 1571 (2010) Test methods for determining the effectiveness of wood preservatives and their performance requirements. Japanese Industry Standards Committee, Japan

18. R Core Team (2016). R: a language and environment for statistical computing. R Foundation for Statistical Computing, Vienna, Austria. https:// www.R-project.org/. Accessed 1 Aug 2021

19. Therneau TM, Lumley T, Elizabeth A, Cynthia C (2021) Package 'survival'. https://cran.r-project.org/web/packages/survival/survival.pdf. Accessed 1 Apr 2021

20. Sakai H, Iwamoto Y, Nakamura Y (2001) Observation of stake impregnated with wood preservative containing copper or zinc as an active ingredient. Wood Preserv 17:114-120

21. Kubo Y, Maeda K, Matsunaga H, Ohmura W, Momohara I (2012) Field test of stakes impregnated with ACQ. Abstracts of the 62th annual meeting of The Japan Wood Research Society. Hokkaido University, Sapporo

22. Kleinbaum DG, Klein M (2012) Survival analysis: a self-learning text, 3rd edn. Springer, New York

23. Woodward BM, Hatfield CA, Lebow ST (2011) Comparison of wood preservatives in stake tests: 2011 progress report. https://www.fpl.fs.fed. us/documnts/fplrn/fpl_rn02.pdf. Accessed 15 Aug 2021

24. Ishiyama N, Horisawa S, Hara T, Yoshida M, Momohara I (2021) Microbiological community structure on logs used for groynes in a riverbank system. J Wood Sci 67:11

\section{Publisher's Note}

Springer Nature remains neutral with regard to jurisdictional claims in published maps and institutional affiliations.

\section{Submit your manuscript to a SpringerOpen ${ }^{\circ}$ journal and benefit from:}

- Convenient online submission

- Rigorous peer review

- Open access: articles freely available online

- High visibility within the field

- Retaining the copyright to your article

Submit your next manuscript at springeropen.com 